\title{
The effects of unconditioned stimulus intensity on conditioned alpha blocking
}

\author{
JOHN T. BRAGGIO and R. THOMPSON PUTNEY \\ Georgia State University, Atlanta, Georgia 30303
}

\begin{abstract}
The relationship between US intensity and conditioned alpha blocking was investigated in a betweengroup design employing 24 human subjects. In all cases, one of three different light intensities was paired with the same tone stimulus. The light intensities used were $.602,1.342$, and $2.065 \log \mathrm{fL}$. The three groups of eight subjects each received the same random sequence and number of stimulus trials in pseudoconditioning, conditioning, and extinction. In pseudoconditioning and extinction, there were 36 unpaired tone and light trials, and in conditioning there were 30 paired tone and light trials. It was found that there was an inverse relationship between light intensity and conditioned alpha blocking. The results were interpreted by extending Pavlov's concept of ultramaximal inhibition.
\end{abstract}

An important characteristic of the EEG is that the presentation of a light stimulus results in the suppression of the alpha rhythm much like the US-UR relationship of peripheral reflex response systems (Adrian \& Matthews, 1934; Bagchi, 1936; Barry \& Beh, 1972; Cruikshank, 1937; Martinson, 1937; Wells, 1959). The results of early classical conditioning studies with the EEG, using the blocking of the alpha rhythm as the UR to light US, documented those phenomena previously reported for other response systems (Beecroft, 1966; Kimble, 1961; Pavlov, 1927; Prokasy, 1965; Razran, 1971). They included forward, delayed, trace, differential, and backward conditioning (Jasper \& Shagass, 1941; Knott \& Henry, 1941; Shagass, 1942; Shagass \& Johnson, 1943; Travis \& Egan, 1938). Therefore, conditioned alpha blocking appeared to be analogous to the classical conditioning obtained with other response systems (Gastaut et al., 1957; Rusinov \& Rabinovich, 1958; Wells, 1963).

The generalization that there is a direct relationship between US intensity and CR frequency or magnitude is not new for classical conditioning (Beecroft, 1966; Kimble, 1961; Prokasy, 1965). More than 50 years ago, Pavlov (1927) showed that CRs did not occur when the US (i.e., concentration of acid) was too weak. In recent years, a positive relationship between US intensity and CR frequency or magnitude has been reported for several response systems (eyelid-Spence \& Taylor, 1951; Walker, 1960; salivation-Feather, Delse, \&

\footnotetext{
The results reported are based on a thesis submitted by the first author to Georgia State University in partial fulfillment of the M.A. degree. The first author would like to express his appreciation to Drs. Ellen and Morrow for their critical reading of the original document. J. T. Braggio is now at the University of North Carolina-Asheville. Requests for reprints should be sent to Dr. John T. Braggio, Department of Psychology, University of North Carolina, Asheville, North Carolina 28804.
}

Bryson, 1967; Razran, 1957; heart rate-Zimney, Stern, \& Fjeld, 1966; GSR-Boring \& Morrow, 1968; Kimmel, Kimmel, \& Silver, 1969). These data support the conclusion that the asymptotic level of the CRs obtained in conditioning depends on the intensity of the US used.

A similar relationship between US intensity and CR magnitude may be present for the EEG, since it has been reported that there is a direct relationship between light intensity and the latency of the alpha blocking response (Cruikshank, 1937). An analysis of experiments that have reported varying degrees of supportive evidence for conditioned alpha blocking suggests that a relatively weak light stimulus can serve as a US (Albino \& Burnard, 1964; Jasper \& Cruikshank, 1937; Jasper \& Shagass, 1941; Shagass \& Johnson, 1943). However, it appears that a relatively weak light stimulus may not serve as an effective US when there are many conditioning trials, since it has been reported by some investigators (Gastaut et al., 1957; Knott \& Henry, 1941; Putney, Erwin, \& Smith, 1972) that the increased effectiveness that the CS acquired during the early portion of the conditioning curve eventually decreased when the CS-US presentations continued beyond 15-20 trials. It may have been the case that the repeated presentation of a relatively weak US resulted in the eventual habituation of the UR during the later portions of conditioning, thereby accounting for the decrease in CR magnitude.

In the present experiment, the effect of US intensity on conditioned alpha blocking was examined. Three absolute US intensities that were perceived as being psychologically different were selected in order to determine their relative effectiveness in producing conditioned alpha blocking. It was predicted that the CS should be a more effective stimulus in blocking the alpha rhythm in conditioning and extinction as the US intensity (i.e., perceived brightness) increased. 


\section{METHOD}

\section{Subjects}

From a pretest sample of 38 undergraduates enrolled in introductory psychology classes. 24 subjects were selected because the resting EEG contained persistent alpha spindles lasting $2 \mathrm{sec}$ or more and having a peak-to-peak amplitude of at least $35 \mu \mathrm{V}$. The group included 18 females and six males who had a median age of 20 and a range of 17 to 26 years.

\section{Apparatus}

The EEG was recorded on a Grass Model 78 electroencephalograph from the scalp of the subject. using gold electrodes placed over the left and right occipital areas $\left(\mathrm{O}_{1}, \mathrm{O}_{2}\right)$ and a reference electrode fastened to the right earlobe. The raw EEG was filtered through a Krohn-Hite variable bandpass filter with the $3-\mathrm{dB}$ points set to pass 7.5-12.5 Hz. After the filtered alpha was rectified (Grass 7P3 driver amplifier) and then integrated (Grass 7 P10 polygraph integrator), it served as the input to the IBM 1800 Data Acquisition and Control System computer. The filtered integrated alpha was recorded by the computer in millivolts when the stimuli were presented. That is, 34 successive .10 -sec readings of the filtered integrated alpha were made, stored on disk for each stimulus period, and punched on IBM cards following each session. Subsequently, the IBM 7094 computer was used to compute the difference scores for each stimulus period by subtracting each reading from its preceding value, with the exception of the first one (i.e.. $X_{2}-X_{1}=$ difference score for first $.10 \mathrm{sec}$, $X_{3}-X_{2}=$ difference score for second .10 sec, etc.) and then again punched on IBM cards. Therefore, for each stimulus period, there were 33 difference scores, one value for each of the 33 successive .10 -sec readings, where the first three preceded stimulus onset and the remaining 30 occurred during the $3.0 \mathrm{sec}$ of stimulus duration.

Stimulus trials were given to the subject when the first seven alpha waves that occurred during $.80 \mathrm{sec}$ satisfied an alpha criterion determined by Digibit programming equipment using a Schmitt trigger to determine the criterion voltage of alpha. The CS was a tone stimulus with a frequency of $450 \mathrm{~Hz}$ and an intensity of about $40 \mathrm{~dB}$ above the level of audibility. The intensities of the three USs were $.602 \mathrm{fL}\left(\mathrm{L}_{1}\right), 1.342 \log \mathrm{fL}\left(\mathrm{L}_{2}\right)$, and $2.065 \log \mathrm{fL}\left(\mathrm{L}_{3}\right)$. The duration of the CSs and USs was always $3.0 \mathrm{sec}$. During conditioning trials, the CS preceded US onset by $1.1 \mathrm{sec}$, and both stimuli overlapped each other for another $1.9 \mathrm{sec}$, at which point the US remained on an additional $1.1 \mathrm{sec}$. The intertrial interval varied from one trial to the next, but was never less than $10.0 \mathrm{sec}$. The actual value of the ITI depended on how long it took the subject to satisfy the alpha criterion once $10.0 \mathrm{sec}$ had elapsed since the last trial.

The CS. US, and CS-US trials were presented while the subject sat in a reclining chair inside an ind ustrial acoustics sound-attenuated chamber. The chair was positioned such that the headrest was $130 \mathrm{~cm}$ from the opaque window. The light stimuli were projected through the opaque window of the test chamber onto a circular target that had a diameter of $30 \mathrm{~cm}$. The tone stimulus was presented through a speaker which was centered immediately below the circular target. Voice contact was made possible from the inside of the sound-attenuated chamber by using a two-way intercom system.

\section{Procedure}

The three groups received the same random sequence and number of stimulus trials in pseudoconditioning, conditioning, and extinction. During each session, all subjects received 102 trials. In pseudoconditioning, there were 36 trials that included a random presentation of 18 tone CSs and 18 light USs. The US trials included six each of the $L_{1}, L_{2}$, and $L_{3}$ light stimuli, which were also randomized. During conditioning. 30CS-US trials were presented to the three groups, but each group received just one light intensity. In extinction, 36 trials of $18 \mathrm{CSs}$ and 18 USs were again presented. As was the case in pseudoconditioning, the 18 US trials included six each of the $L_{1}, L_{2}$, and $L_{3}$, light stimuli. The same number of light stimuli were included in extinction as in pseudoconditioning in order to assess the presence of CRs occurring to CS-only trials in extinction without changing the motivational or arousal state of the subject.

After receiving all the trials, the subject was given a questionnaire that was concerned with the perceived intensity of the CSs and USs. The questionnaire requested the subject to state how intense he thought the CS had been by assigning a score of 1 through 7, where 1 represented a stimulus of very low intensity and 7 a stimulus of very high intensity. Similarly, the subject was also asked to judge the intensity of the three USs that appeared in pseudoconditioning and extinction and to indicate the intensity of the light that was paired with the tone.

\section{RESULTS}

\section{Data Reduction}

The mean proportion reduction was computed by dividing the session average of the three readings obtained just before stimulus onset into 15 or 30.10 -sec values following stimulus onset for each subject. All statistical analyses on the CS-only and CS-US trials were performed on the individual blocks of trials for each subject, using the mean proportion for $1.1,1.2$, 1.3 , and $1.4 \mathrm{sec}$ after tone onset. Since the ISI was $1.1 \mathrm{sec}$, there were 11 values before the 19 values after light onset during the conditioning trials. Although the mean proportion reduction was computed by using these three .10-sec intervals immediately following the US onset rather than during the ISI, it is important to notice that the UR was not included in the measurement since it occurred later in the interval. A careful inspection of the data showed that the onset of the CR was separated in time from the onset of the UR by at least $.2 \mathrm{sec}$. Accordingly, UR magnitude was assessed for the three groups by examining the mean of the proportion reduction that occurred for $1.7,1.8$, 1.9 , and 2.0 sec after stimulus onset in conditioning and $.7, .8, .9$, and $1.0 \mathrm{sec}$ after tone onset in pseudoconditioning and extinction. In each case, the rationale for selecting the four values for the tone and light trials was to obtain the greatest separation between the various curves. Putney (1973) showed that conditioned alpha blocking occurred from 1.1 to $1.4 \mathrm{sec}$ after stimulus onset, and in the present experiment the greatest suppression of the alpha rhythm occurred $.7 \mathrm{sec}$ after light onset in all three conditions of pseudoconditioning, conditioning, and extinction.

\section{Pseudoconditioning}

The results of the pseudoconditioning procedure produced obvious differences in the pattern of blocking of URs and the responses to the CSs. This difference is shown in Figure 1A by the 15 successive .10-sec readings following light and tone onset, graphed in blocks of six trials. As previously stated, the statistical analyses on these data were performed on the individual blocks of trials for each subject by computing the mean proportion reduction for 


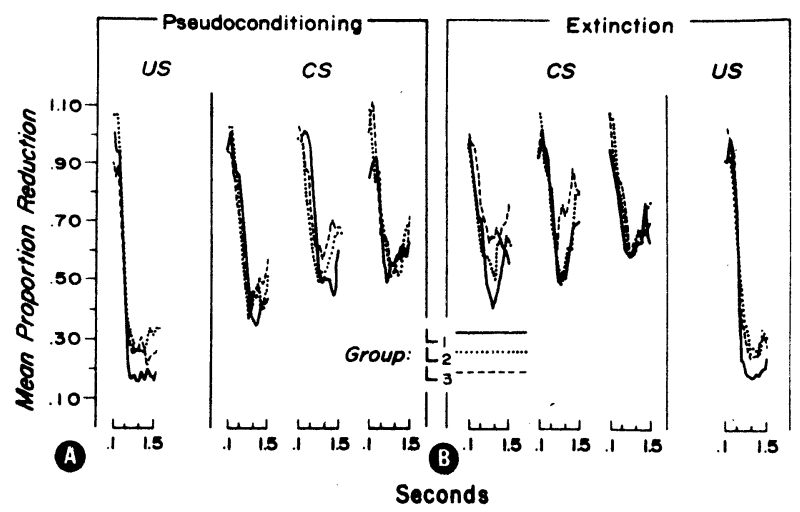

Figure 1. The pattern of blocking of USs and CSs in pseudoconditioning (A) and extinction (B) for the three groups. The successive set of curves represents the average of six trials for the first 1.5 sec after stimulus onset. The mean proportion reduction was computed by dividing the mean of the three prestimulus difference scores into each of the 15.10 -sec readings during stimulus duration.

1.1-1.4 sec after CS onset and .7-1.0 sec after US onset. When the pseudoconditioning data were analyzed using the Mann-Whitney $U$ test, it was found that the US for Group $L_{1}$ did not differ from the US for Group $L_{2}(U=24, p>.05)$ or Group $L_{3}(U=26$, $\mathrm{p}>.05)$. However, there was a significant difference between all USs and CSs $(T=16.5, \mathrm{p}<.01)$, using a Wilcoxon matched-pairs signed-ranks test. The presence of a significant difference between the first and third block of CS-only trials in pseudoconditioning $(\mathrm{T}=35.5, \mathrm{p}<.01)$ indicated that the CS habituated. By the third block of CS trials, the three groups were not significantly different from each other $(\mathrm{H}=.03$, $\mathrm{p}>.50$ ) when tested with the Kruskal-Wallis one-way analysis of variance.

\section{Conditioning}

The conditioning trials differed from the Pseudoconditioning trials in that pairing the CS with a different US intensity resulted in the increased effectiveness of the tone in blocking the alpha rhythm, for some light intensities but not for others. This is seen in Figure 2 as the mean proportion reduction obtained during conditioning for the three groups. The statistical analyses were again performed on the mean proportion reduction recorded 1.1, 1.2, 1.3, and $1.4 \mathrm{sec}$ after stimulus onset. Individual comparisons between successive blocks of six trials in conditioning supported the fact that conditioned alpha blocking occurred only for the lowest intensity level. For Group $L_{1}$, the last block of CS trials in pseudoconditioning was significantly different from the first $(T=2, p<.05)$, second $(T=3, p<.05)$, third $(\mathrm{T}=1, \mathrm{p}<.05)$, and fifth $(\mathrm{T}=2, \mathrm{p}<.05)$ blocks of conditioning trials, with a nonsignificant difference for the fourth $(T=5, p>.05)$. Similar comparisons were performed for the other two groups, but none were significant. Even though there was clear evidence of conditioned alpha blocking in the early portion of the conditioning curve of Group $L_{1}$, the effectiveness of the CS in blocking the alpha rhythm eventually decreased, since the difference between the third and fourth block approached significance $(X=$ $2, p<.10)$ and the comparison between the third and fifth block was marginally significant $(X=1$, $\mathrm{p}<.06$ ). Between-group comparisons indicated that for all five blocks of conditioning trials taken together, $\mathrm{L}_{1}$ was significantly different from $\mathrm{L}_{3}(\mathrm{U}=11$, $p<.05)$, but not from $L_{2}(U=21, p>.05)$. Thus, these results suggest that there was an inverse relationship between the degree of conditioned alpha blocking and US intensity rather than the expected direct relationship.

Inspection of Figure 2 suggests that there may have been an inverse relationship between US intensity and conditioned alpha blocking. However, it was found that the US for Group $L_{1}$ was not significantly different from that for Group $L_{2}(U=22, p>.05)$ or Group $L_{3}$ $(\mathrm{U}=26, \mathrm{p}>.05)$. A closer analysis of the conditioning records suggested that those subjects who showed the greatest degree of conditioned alpha blocking also had a larger UR magnitude. The relationship between the magnitude of the CR and UR was determined by assigning ranks based on increasing mean proportion reduction to the CSs and USs in conditioning that were recorded for the 24 subjects, resulting in a significant rank correlation between CR and UR magnitude $(\mathrm{r}=.55, \mathrm{p}<.05)$.

The pseudoconditioning and conditioning trials were also analyzed in blocks of two trials instead of blocks of six trials as was shown in Figure 2 in order to observe more closely the habituation and conditioning trends for the three groups. For each block of two trials, the mean proportion reduction was computed

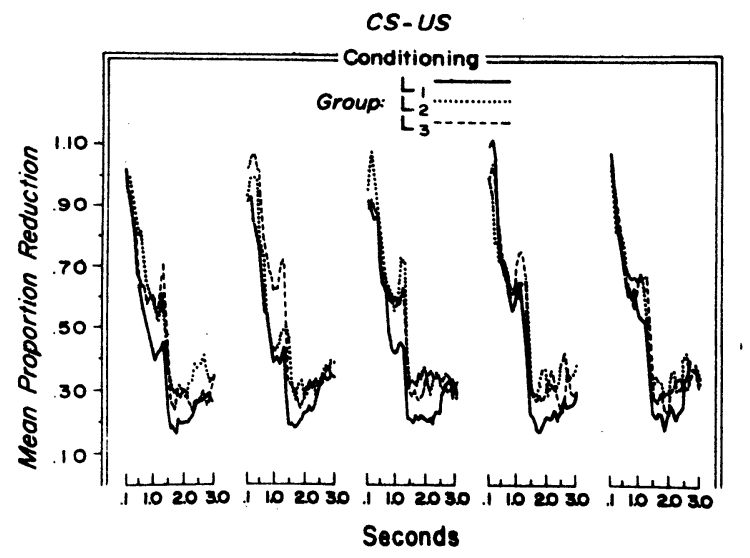

Figure 2. The pattern of blocking for the CS-US trials in conditioning for the three groups. The successive set of curves represents the average of six trials for the first 3.0 sec after stimulus onset. The mean proportion reduction was computed by dividing the mean of the three prestimulus difference scores into each of the 30 .10-sec readings during CS-US duration. 


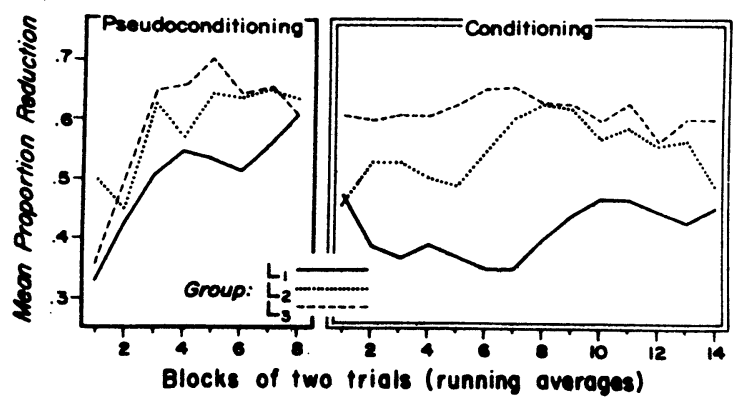

Figure 3. Successive blocks of two trials showing the mean proportion reduction obtained for the three groups in pseudoconditioning and conditioning.

for $1.1,1.2$, and $1.3 \mathrm{sec}$ after stimulus onset. Running averages seen in Figure 3 were computed for each block, with the exception of the first, by computing the mean of the preceding and succeeding values. Although the data were graphed in the form of running averages, all statistical analyses were performed on the individual two trial blocks prior to averaging. An analysis on the difference scores computed by subtracting the mean of the last two pseudoconditioning CS trials from the mean of the 30 conditioning trials for each subject showed that there was a significant treatment effect between the groups $(\mathrm{H}=6.41, \mathrm{p}<.05)$. While there appears to be an immediate decrease in the mean proportion reduction on the first block of conditioning trials for both Group $L_{1}$ and Group $L_{2}$, the last block of pseudoconditioning was not significantly different from the first block of conditioning for either group. Other individual comparisons indicated that for the average of the 30 conditioning trials, Group $L_{1}$ was significantly different from Group $L_{3}(U=12$, $p<.05)$, but not from Group $L_{2}(U=27, p>.05)$. Although for the conditioning trials, Group $L_{1}$ was not different from $G$ roup $L_{2}$, the trend across trials was not the same. While Group $L_{1}$ showed a decreasing monotonic trend across trials from the first to the seventh block, Group $L_{2}$ showed an increasing monotonic trend. This difference in trends was assessed by subtracting the first block from the seventh block for each subject and comparing the difference scores for the two groups, using the Mann-Whitney U test, which was marginally significant $(U=14$, $\mathrm{p}<.06)$.

\section{Extinction}

Following conditioning, the CSs and USs were again presented without being paired, but this time in extinction. These data are shown in Figure 1B. When the third block of CS trials in pseudoconditioning was compared with the first of the CS trials in extinction, none of the comparisons were significant. However, the absence of group differences in extinction was accompanied by a progressive increase in the mean proportion reduction for the last two blocks of conditioning trials followed by a sharp decrease on the first block of extinction trials that approached significance $(T=6, p<.10)$ for Group $L_{1}$ only. Analysis of the first six extinction trials for Group $L_{1}$ showed that the mean proportion reduction decreased from the first to the third and increased from the fourth to the sixth. It was found that the third trial (.51) had a significantly lower mean proportion reduction than the first trial (.63) for Group $L_{1}$ when tested with the sign test $(X=1, p<.05$, one-tail); but nonsignificant differences were obtained for the other two groups $\left(\mathrm{L}_{2}\right.$-first trial $=.53$, third trial $=.51, \mathrm{X}=3$, $\mathrm{p}>.05 ; \mathrm{L}_{3}$-first trial $=.64$, third trial $=.77, \mathrm{X}=3$, $p>.05)$. Finally, the absence of a significant contrast between the USs in pseudoconditioning with those in extinction $(T=61.5, p>.05)$ suggested that the repeated presentations of the light during the test session did not result in the habituation of those stimuli.

\section{Latency}

A common feature of the CS-only trials and the CS-US trials was that the pattern of blocking resembled a reversed "J" function. To determine whether the latency of the smallest value at the base of the " $J$ " function varied in pseudoconditioning and in conditioning, the smallest value that occurred from .2 to $1.2 \mathrm{sec}$ after tone onset was selected for each trial. Figure 4A shows a histogram of the latencies for the three groups in pseudoconditioning and in conditioning. It was found that there was not a significant treatment effect between the three groups with respect to the latency of all CSs in pseudoconditioning $(H=1.01, p>.05)$. None of the between-group comparisons were signficant when the latency of the smallest value was examined for conditioning. However, individual comparisons between pseudoconditioning and conditioning indicated that there was a significant difference for Group $L_{1}(T=1, p<.05)$, but no significant difference for Group $L_{2}(T=9, p>.05)$ or Group $L_{3}$ $(T=11, p>.05)$, thus suggesting that CRs have longer latencies than other responses.
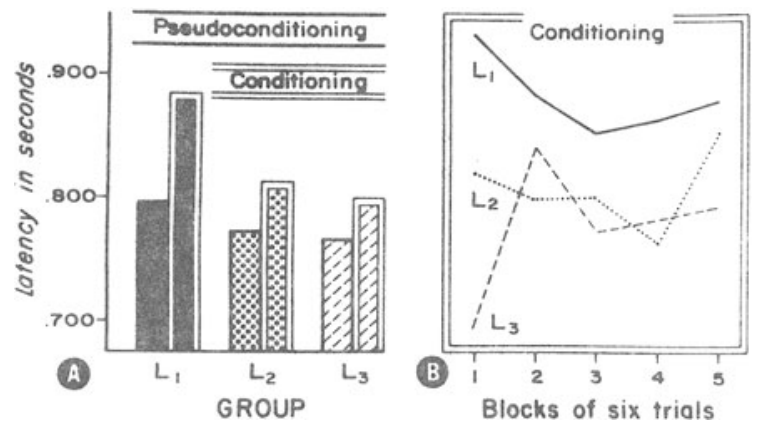

Figure 4. The latency of the smallest value that occurred at the base of the reversed " $\mathrm{J}$ " curves in conditioning and extinction (A) and across the five blocks of trials in conditioning (B) for the three groups. 
Next, changes in latency measure across blocks of six conditioning trials were examined. These data are shown in Figure 4B. While the form of the latency curve for Group $L_{1}$ was relatively regular, the one for Group $\mathrm{L}_{3}$ showed two reversals on the first to the second and on the second to the third blocks of conditioning trials. With the exception of a statistical difference that approached significance between Group $L_{1}$ and Group $L_{3}$ on the first block of conditioning trials $(U=14, p<.06)$, none of the other between-group comparisons were close to being significant. More importantly, across the five blocks of conditioning trials there was not a significant decreasing linear trend in the latency curve for Group $L_{1}(L=376, p>.05)$, when tested with the $L$ test (Page, 1963). Even though there was not evidence of conditioned alpha blocking on the fourth block of conditioning trials for Group $L_{1}$, the latency of the smallest value was not significantly different between the fourth and third $(T=10.5, \mathrm{p}>.05)$ or the fourth and fifth $(T=11, \mathrm{p}>.05)$ blocks. Therefore, these data suggest that the decrease in the magnitude of the $\mathrm{CR}$ during the later portions of the conditioning curve of Group $L_{1}$ was not accompanied by a decrease in the latency of that response.

\section{Perceived Stimulus Intensity}

Finally, the responses from the stimulus intensity questionnaires obtained from the 24 subjects were analyzed in order to determine the perceived distance of the three lights used as USs. These data are shown in Figure $5 \mathrm{~A}$ as median intensity scores for the three groups. The three groups were found to be significantly different from each other $(\mathrm{H}=11.08, \mathrm{p}<.01)$. When individual comparisons were performed, it was found that $L_{2}$ was significantly more intense than $L_{1}(U=8$, $p<.01)$ but significantly less intense than $L_{3}(U=9$, $\mathrm{p}<.01)$.

A similar analysis was carried out for the CSs. The median perceived intensity scores for the three groups are shown in Figure 5B. Since there was not a significant treatment effect $(\mathrm{H}=1.49, \mathrm{p}>.50)$, it can be concluded that pairing a tone with a different US did not influence the perceived intensity of the CS. Therefore, these data suggest that the expected relationship between the absolute and perceived intensity of a stimulus was obtained.

\section{DISCUSSION}

The conditioning data indicated that the CS became significantly more effective in blocking the alpha rhythm after it was paired with the least intense US but not with the two more intense light stimuli (see Figures 2 and 3 ). In addition, the latency of the smallest value at the base of the reversed " $\mathrm{J}$ " curve was significantly longer in conditioning than in pseudoconditioning only for Group $L_{1}$ (see Figure 4). This delay in the
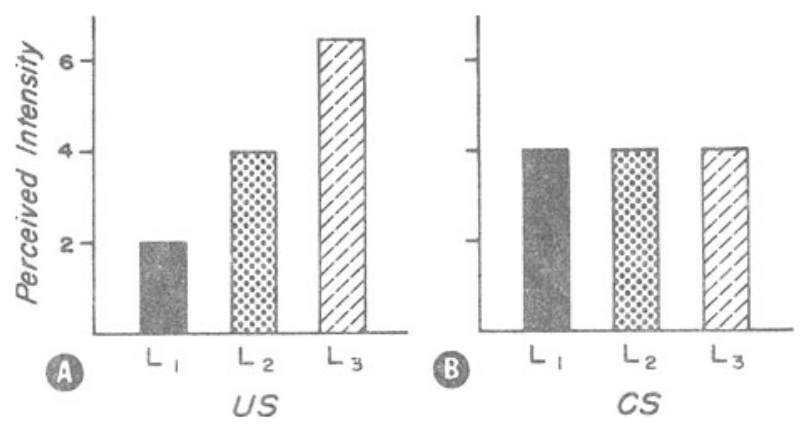

Figure 5. The perceived intensity of the US paired with the CS during conditioning for the three groups (A), as well as the perceived intensity of the CS $(B)$. In all cases, the height of the histogram bars represents the median perceived intensity score for that group.

occurrence of the smallest value at the base of the reversed " $\mathrm{J}$ " curve is analogous to inhibition of delay that was first reported by Pavlov (1927), who pointed out that the CR did not occur until just prior to UR onset. On the basis of these two facts, it was concluded that clear evidence for conditioned alpha blocking occurred only in Group $\mathrm{L}_{1}$.

The finding of the present study that there was an inverse relationship between US intensity cannot be explained in terms of the habituation of the light stimulus following repeated presentation, since all three USs were equally effective in blocking the alpha rhythm in both pseudoconditioning and extinction Further, it should be recalled that a habituation hypothesis is not consistent with the results of the present experiment, since it would have incorrectly predicted that the least intense US should have been the least effective light stimulus in producing conditioned alpha blocking. In point of fact, the least intense light was the only one that produced clear evidence of conditioned alpha blocking.

Although the inverse relationship between US intensity and conditioned alpha blocking was unexpected, the results of the present experiment are consistent with the results of previously reported EEG conditioning studies in three different ways. First, the conditioning curve for Group $\mathrm{L}_{1}$ did show clear evidence that stable CRs were present. It is of interest to contrast the conditioning curve for Group $L_{1}$ (see Figure 3) with the one reported by Putney, Erwin, and Smith (1972) for their condition in which a response was made at light offset as in the present study, and the US intensity used was similar to the one used here. In both experiments, the form of the pseudoconditioning curve appeared to be monotonically increasing, while the form of the conditioning curves was monotonically decreasing over the first 15-20 trials. Similar conditioning curves were also found by other investigators who also used a relatively weak US and found evidence of conditioning (Jasper \& Cruikshank, 1937; Jasper \& Shagass, 1941; Putney, 1973; Shagass. 
1942; Shagass \& Johnson, 1943). Second, the decreasing effectiveness of the CS in blocking the alpha rhythm in the conditioning curve of Group $L_{2}$ represents little or no support for the occurrence of conditioning. These data resemble the results of those investigators (Escover et al., 1964; Milstein, 1965; Stern et al., 1961) who used a relatively intense US and only found evidence of sensitization. Third, with the most intense light stimulus, not even sensitization occurred during conditioning. In fact, the most intense US did not seem to influence the pattern of alpha blocking to the CS in conditioning, since none of the comparisons with the tone-only trials in pseudoconditioning were significant. Further, the conditioning curve in Figure 3 was just an extension of habituation for $L_{3}$. Therefore, a close examination of previous studies on conditioned alpha blocking as well as the findings of the present experiment suggest that, over the range of stimulus values studied, there is an inverse, rather than a direct, relationship between US intensity and the magnitude of the CR.

The increase in the proportion reduction of the conditioning curve for Group $L_{1}$ beyond the 18th trial could be interpreted as a nonassociative change. It has been suggested that conditioned alpha blocking can be accounted for in terms of the return of the orienting response $(\mathrm{OR})$ to the CS that occurs when the tone is first paired with the US during the early conditioning trials (Davidoff \& McDonald, 1964; Milstein, 1965; Stern et al, 1961). Even the immediate drop in the conditioning curves for the $L_{1}$ and $L_{2}$ groups that occurred on the first two trials when the tone was paired with the light cannot be explained by those assumptions and predictions generated by an OR explanation. An OR explanation predicts that the amount of drop in the conditioning curve resulting from the pairing of a habituated tone with a light stimulus should be a function of the absolute intensity of the light stimulus used. In the present experiment, the greatest decrease in the conditioning curve across the first 15 trials was found for Group $L_{1}$ rather than for the other two groups. Further, since additional conditioning trials resulted in a decreasing monotonic trend for Group $L_{1}$ that continued beyond the 15th trial, it can be concluded that repeated tone-light pairings resulted in a gradual associative change instead of the abrupt occurrence of a sensitized response.

The inverse light-intensity relationship between light intensity and the degree of blocking the alpha rhythm could have occurred because the subjects did not follow the experimenter's instructions and closed their eyes when the more intense stimuli came on, since many of the subjects reported sponaneously to the experimenter that the $L_{2}$ and $L_{3}$ lights were "very bright" and "painfully bright," respectively. Of course, by closing the eyes, the intensity and the degree of painfulness associated with the $L_{2}$ and $L_{3}$ light would decrease. An anticipatory tendency to close the eyes with the higher light intensities would require a warning stimulus to inform the subject when the intense USs were to appear. During conditioning, the CS could have functioned as a warning stimulus so that those subjects receiving either the $L_{2}$ or $L_{3}$ USs could have closed their eyes during tone onset, a fraction of a second prior to light onset, thereby attenuating the UR. If this response strategy was indeed adopted by the subjects in the $\mathrm{L}_{2}$ and $\mathrm{L}_{3}$ groups, then the unattenuated UR should still be recorded under those conditions where the tone stimulus did not reliably precede light onset. Because the URs to the three USs were not significantly different from each other in pseudoconditioning and extinction as compared with conditioning, it is concluded that the obtained results cannot be explained in terms of voluntary eye closing on the part of the subject.

Alternatively, the decreased responding to intense stimuli could have occurred involuntarily on the part of the subject. Pavlov (1927) called the decreased responding generated by CSs exceeding a certain intensity ultramaximal inhibition. "Pavlov thought of this as a protective inhibition, and he gave great emphasis to the fact that when the physiological stimulus becomes too intense, which might lead to destruction or damage to nerve cells, the organism protects itself through inhibition" (Gantt, 1958, p. 173). There are several lines of evidence that support the extension of the concept of ultramaximal inhibition to explain the results of the experiment. A recent study by Barry and Beh (1972) suggested that the change in amplitude of the EEG showed a nonmonotonic relationship to the intensity of the light stimulus when three different intensities of $1.30,1.98$, and $2.67 \log \mathrm{fL}$ were used in which the maximum blocking occurred for the middle amplitude. Cruikshank (1937) reported that there was an inverse relationship between blocking time and light intensity when the stimulus values ranged from 1.0 to $10^{-5} \mathrm{fL}$. There is also extensive evidence from the Soviet literature (Razran, 1961) that there is an inverted " $U$ " function between shock intensity and the magnitude of vasodilation and/or vasoconstriction.

The concept of ultramaximal inhibition can be extended to include the effects of the $L_{1}, L_{2}$, and $L_{3}$ light intensities on the alpha rhythm as follows. The fact that there was a significant rank order correlation between the degree of conditioned alpha blocking and UR magnitude would suggest that the effectiveness of a particular light stimulus as a US in conditioning is related to the effect which it has in blocking the alpha rhythm. The $L_{1}$ light was relatively more effective in blocking the alpha rhythm, and at the same time it served as the only effective US in producing conditioned alpha blocking. When the intensity of the US was increased to that of $\mathrm{L}_{2}$ or even $\mathrm{L}_{3}$, then the degree of blocking the alpha rhythm decreased and the 
amount of conditioned alpha blocking decreased as well. Several assumptions can be generated from these facts. First, the relationship between light intensity and its effect on alpha blocking can be described as an inverted " $U$ " function. Second, the effectiveness of a light stimulus in functioning as an adequate US is related to the amount of blocking in the alpha rhythm that results. Third, those lights on the ascending arm of the inverted "U" function are reinforcing USs, while those on the descending arm are inhibitory.

From the three assumptions, it is possible to explain the results of the present experiment using the following argument. The transition from pseudoconditioning to conditioning resulted in a sharp decrease in the mean proportion reduction for both $\mathrm{L}_{1}$ and $\mathrm{L}_{2}$ groups, which probably was due to a sensitization effect resulting from the pairing of the CS with the US for the first time (see Figure 3). However, it is important to note the difference between the conditioning curves for $L_{1}$ and $L_{2}$. Although the initial decrease in the mean proportion reduction for both groups may have been due to sensitization, the curve for Group $L_{1}$ continued to decrease up to Trial 18 , while that of Group $\mathrm{L}_{2}$ increased across the conditioning trials. The conclusion that sensitization contributed very little to the $L_{1}$ conditioning curve can be inferred from the significantly longer latency of the smallest value at the base of the reversed "J" pattern of blocking. The decrease in the Group $\mathrm{L}_{1}$ conditioning curve was due to repeated pairing of the CS with a more effective stimulus (i.e., conditioning), while the increase in the Group $L_{2}$ curve was due to the repeated pairing of the CS with a negative or less effective US (i.e., conditioned inhibition). Similarly, the $L_{3}$ intensity was the least effective of the US during conditioning, as evidenced by the absence of sensitized effect of the light stimulus on the tone for the first few conditioning trials. In fact, for $\mathrm{L}_{3}$ the mean proportion reduction in the CS-only trials did not differ significantly from the CS-US trials.

The explanations that have been considered thus far do not account for the decrease in the magnitude of the CR that was obtained on Blocks 5 and 6 for Group $L_{1}$ during conditioning. It is possible that the decreased effectiveness of the CS in blocking the alpha rhythm for the last 10 conditioning trials represents inhibition of reinforcement (Knott \& Henry, 1941; Putney, Erwin, $\&$ Smith, 1972). Originally, inhibition of reinforcement was proposed by Hovland (1936) as an explanation of the decrement in the level of GSR conditioning when many CS-US trials were administered. Inhibition of reinforcement appeared to be a possible explanation for the ascending portion of the $L_{1}$ conditioning curve, since the magnitude of the $\mathrm{CR}$ decreased as a function of relatively massed conditioning trials and the degree of conditioned alpha blocking was greater on the third than on the first extinction trial. These observations are consistent with
Hovland's hypothesis that inhibition of reinforcement occurs as a function of many CS-UR pairings, as the CS acquires some sort of inhibition that prevents the CR from coming to expression as long as it is paired with the US. By removing the US, the inhibition dissipates and the CR is again expressed as a change in performance.

The position that has been expressed in the present paper is that conditioned alpha blocking may be considered "labile" responses because their occurrence depends on a variety of factors such as the intensity of the US, the number of conditioning trials, and possibly the ISI. This does not necessarily mean that classical conditioning of the EEG is any more or less labile than the classical conditioning in the eyelid, heart rate, GSR, or salivation response systems (Kimble, 1961; Stewart, Stern, Winokur, \& Fredman, 1961; Razran, 1971). Some investigators (Visser, 1961; Walter, 1961) have suggested that, for the EEG response system, pairing a CS and a US produces labile responses that could be best interpreted without accounting for these changes in terms of classical conditioning phenomena. Such conclusions concerning the conditionability of the EEG are premature in that they must be preceded by parametric investigations of those variables that have been known for over 50 years to determine whether or not CRs do occur. It should not be necessary to remind the reader that the present study is the first US-intensity experiment and only the second parametric investigation on the EEG, even though the phenomenon has been known for more than 40 years. The results of the present study do suggest that although sensitization may account for the initial decrease in the mean proportion reduction on the first few conditioning trials, US intensity still determines the eventual asymptotic level of the conditioning curve. Although classical conditioning of the EEG may produce labile CRs, they still behave in much the same way as those that have been obtained on other response systems.

\section{REFERENCES}

Adrian, E. D., \& Matthews, B. H. C. The Berger rhythm: Potential changes from the occipital lobes in man. Brain, 1934, 57, 355-385.

Albino, R., \& Burnard, G. Conditioning of the alpha rhythm in man. Journal of Experimental Psychology, 1964, 67, 539-544.

BAGCHI, G. K. The adaptation and variability of response of the human brain rhythm. Journal of Psychology, 1936, 3 , 463-485.

BARRY, R. J., \& BEH, H. C. Desynchronization of the alpha rhythm of the EEG as a function of intensity of visual stimulation. Psychonomic Science, 1972, 26, 241-242.

BeEcroft, R. S. Classical condioning. Goleta, Calif: Psychonomic Press, 1966.

Boring, F. W., \& Morrow, M. C. Effects of UCS intensity upon conditioning and extinction of the GSR. Journal of Experimental Psychology, 1968, 77, 566-571. 
Cruikshank, R. M. Human occipital brain potentials as affected by intensity-duration variables of visual stimulation. Journal of Experimental Psychology, 1937, 21, 625-641.

Davidoff, R. A., \& McDonald, D. G. Alpha blocking and autonomic responses in neurological patients. Archives of Neurology (Chicago), 1964, 10, 283-292.

EsGover, H. B., Torres, A. A., TAYlor, R. M., Wilkens, B. \& Mulitz, S. Contingent alpha blocking and sensitization. Nature, 1964, 201, 1247-1248.

Feather, B. W., Delse, F. C., \& Bryson, M. R. Human salivary conditioning: Effect of unconditioned stimulus intensity. Journal of Experimental Psychology, 1967, 74, 389-392.

Gantr. W. H. Pavlov. In M. A. B. Brazier (Ed.), The central nervous system and behavior: Transactions of the first conference. New York: Josiah Macy, Jr., Foundation, 1958. Pp. 163-186.

Gastaut, H., Jus, C., Morrell, F., Storn van Leeuwen, W., Dongier, S., Naquet, R., Regis, H., Roger, A., Bekkering, D.. KAMP. A.. \& WERrE, J. Etude topographique des réactions électroencéphalographiques conditionées chez 'homme. Electroencephalography and Clinical Neurophysiology, 1957, 9, 1-34.

Hovland. C. I. "Inhibition of reinforcement" and phenomena of experimental extinction. Proceedings of the National Academy of Sciences, 1936, 22, 430-433.

JASPER, H. H., \& CRUIKSHANK, R. M. Electroencephalography. II. Visual stimulation and the after image as affecting the occipital alpha rhythm. Journal of General Psychology, 1937. 17. 29-48.

Jasper, H., \& Shagass, C. Conditioning of the occipital alpha rhythm in man. Joumal of Experimental Psychology, 1941, 28, 373-387.

Kimble, G. A. Hilgard and Marquis' Conditioning and learning (rev. ed.). New York: Appleton-Century-Crofts, 1961.

Kimmel, H. D., Kimmel, E. B., \& Silver, A. I. The effect of UCS intensity in classical and avoidance conditioning. Conditional Reflex, 1969, 4, 32-51.

KNotT, J. R., \& Henry, C. E. The conditioning of the blocking of the alpha rhythm of the human electroencephalogram. Journal of Experimental Psychology, 1941, 28, 134-144.

Martinson, B. Effects of visual and auditory stimuli on brain waves. Proceedings of the Iowa Academy of Sciences, 1937. 45. 271-273.

Milstein, V. Contingent alpha blocking: Conditioning or sensitization? Electroencephalography and Clinical Neurophysiology, 1965, 18, 272-277.

PAGE. E. B. Ordered hypotheses for multiple treatments: A significance test for linear ranks. American Statistical Association Journal, 1963, 58, 216-230.

Pavlov, I. P. Conditioned reflexes (G. B. Anrep trans.). London: Oxford University Press, 1927.

Prokasy, W. F. Classical conditioning. New York: AppletonCentury-Crofts, 1965.

Putney, R. T. Conditioned alpha blocking re-examined with the measurement of individual wave amplitudes. Electroencephalography and Clinical Neurophysiology, 1973, 34, 485-493.
Putney, R. T., Erwin, T. J., \& Smith, T. S. The facilitation of conditioned alpha blocking with an overt response. Psychonomic Science, 1972, 26, 16-18.

RAzRAN, G. The dominance-contiguity theory of the acquisition of classical conditioning. Psychological Bulletin, 1957, 54, 1-46.

RAzRAN, G. The observable unconscious and the inferable conscious in current Soviet psychophysiology: Interoceptive conditioning, semantic conditioning and the orienting reflex. Psychological Review, 1961, 68, 81-147.

Razran, G. Mind in evolution: An east-west synthesis of learned behavior and cognition. Boston: Houghton-Mifflin, 1971.

Rusinov, V. S., \& Rabinovich, M. Y. Electroencephalographic researches in the laboratories and clinics of the Soviet Union. Electroencephalography and Clinical Neurophysiology, 1958, Suppl. 8, 1-36.

ShaGAss, C. Conditioning the human occipital alpha rhythm to a voluntary stimulus: A quantitative study. Journal of Experimental Psychology, 1942, 31, 367-379.

Shagass, C., \& Johnson, E. P. The course of acquisition of a conditioned response of the occipital alpha rhythm. Journal of Experimental Psychology, 1943, 33, 201-209.

Spence, K. W., \& TAYlor, J. A. Anxiety and strength of the UCS as determinants of the amount of eyelid conditioning. Journal of Experimental Psychology, 1951, 42, 183-188.

Stern, J. A., Das, K. C., Anderson, J. M., Biddy, R. L., \& SURPhlis, W. "Conditioned" alpha desynchronization. Science, 1961, 134, 388-389.

Stewart, M. A., Stern, J. A., Winokur, G., \& Fredman, S. 1 An analysis of GSR conditioning. Psychological Review, 1961, 68, 60-67.

Travis, L. E., \& Egan, J. B. Conditioning of the electrical response of the cortex. Journal of Experimental Psychology, 1938, 22, 524-531.

VISSER, S. L. Correlations between the contingent alpha blocking, EEG characteristics and clinical diagnosis. Electroencephalography and Clinical Neurophysiology, 1961, 13, 768-774.

WALTER, W. G. The vocabulary of psycho-physiology. Electroencephalography and Clinical Neurophysiology, 1961, 13, 447-448.

W ALKER, E. G. Eyelid conditioning as a function of intensity of conditioned and unconditioned stimuli. Journal of Experimental Psychology, 1960, 59, 303-311.

Wells, C. E. Modification of alpha-wave responsiveness to light stimuli by juxtaposition of auditory stimuli. Archives of Neurology (Chicago), 1959, 1, 689-694.

WELLS, C. E. Electroencephalographic correlates of conditioned responses. In N. Glaser (Ed.), EEG and behavior. New York: Basic Books, 1963. Pp. 60-108.

Zimney, G. H., Stern, J. A., \& Fueld, S. P. Effects of CS and UCS relationships on electrodermal response and heart rate. Journal of Experimental Psychology, 1966, 72, 177-181.

(Received for publication March 12, 1975; accepted May 8, 1975.) 